
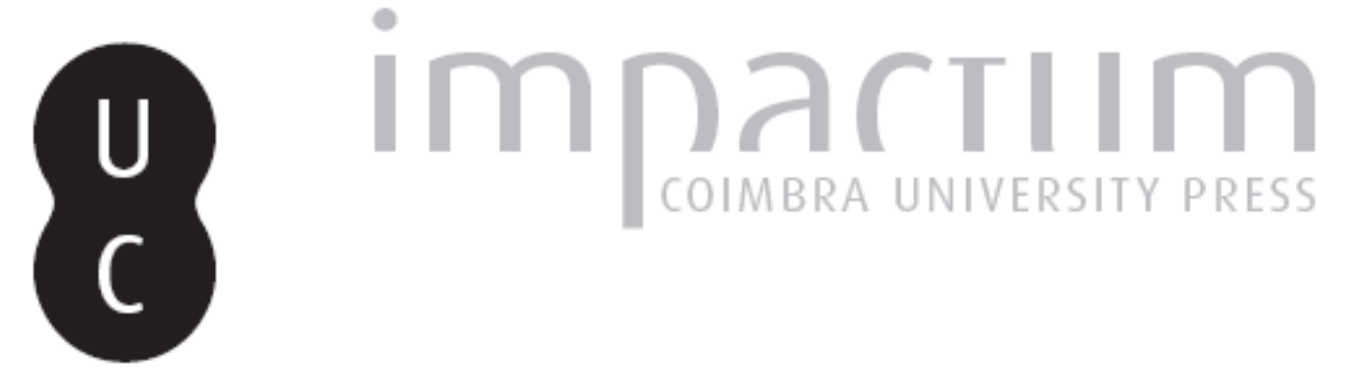

\title{
O voto jovem e as eleições para o Parlamento Europeu
}
Autor(es):
Valente, Isabel Maria Freitas; Cunha, Alice
Publicado por: Centro de Informação Europe Direct de Aveiro; Centro de Estudos Interdisciplinares do Século XX

URL

persistente:

URI:http://hdl.handle.net/10316.2/33976

DOI:

DOI:http://dx.doi.org/10.14195/1647-6336_11_5

Accessed : $\quad$ 26-Apr-2023 09:24:59

A navegação consulta e descarregamento dos títulos inseridos nas Bibliotecas Digitais UC Digitalis, UC Pombalina e UC Impactum, pressupõem a aceitação plena e sem reservas dos Termos e Condições de Uso destas Bibliotecas Digitais, disponíveis em https://digitalis.uc.pt/pt-pt/termos.

Conforme exposto nos referidos Termos e Condições de Uso, o descarregamento de títulos de acesso restrito requer uma licença válida de autorização devendo o utilizador aceder ao(s) documento(s) a partir de um endereço de IP da instituição detentora da supramencionada licença.

Ao utilizador é apenas permitido o descarregamento para uso pessoal, pelo que o emprego do(s) título(s) descarregado(s) para outro fim, designadamente comercial, carece de autorização do respetivo autor ou editor da obra.

Na medida em que todas as obras da UC Digitalis se encontram protegidas pelo Código do Direito de Autor e Direitos Conexos e demais legislação aplicável, toda a cópia, parcial ou total, deste documento, nos casos em que é legalmente admitida, deverá conter ou fazer-se acompanhar por este aviso.

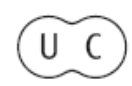


DEBATER

A EUROPA

jul-dez 2014

QUE EUROPA(S)?

CONTEXTOS E DESAFIOS 


\title{
O voto jovem e as eleições para o Parlamento Europeu
}

\author{
Isabel Maria Freitas Valente \\ Doutora em Altos Estudos Contemporâneos \\ Investigadora Integrada do CEIS20-UC \\ Investigadora de Pós-doutoramento FCT / CEIS20-UC \\ Membro do Team Europe da Comissão Europeia \\ E-mail: valente.isa@gmail.com \\ Alice Cunha \\ Doutora em História Contemporânea \\ Investigadora Integrada IHC-UNL \\ Investigadora de Pós-doutoramento FCT / IHC-UNL \\ E-mail: alice_mpbc@portugalmail.pt
}

Citizen and Citizenship are powerful words. They speak of respect, of rights, of dignity.

Nancy Fraser; Linda Gordon, Civil Citizenship against Social Citizenship?, 1996

\section{Resumo}

As eleições de Maio de 2014 para o Parlamento Europeu (PE), a questão da mobilização eleitoral está, de novo, no cerne do debate, procurando os partidos, os governos e a própria União Europeia (UE) motivar o eleitor a votar e combater a abstenção, cada vez mais elevada. Desafio ainda mais particular é cativar o voto dos jovens entre os 18 e os 24 anos. 
Este ensaio pretende, assim, focar especificamente a questão do voto jovem, cuja própria UE identifica como sendo uma preocupação. Nesse sentido, o ensaio começa com uma breve revisão da literatura em português sobre as eleições para o PE e sobretudo sobre o voto jovem e a participação política dos jovens, com apontamentos para a cidadania; e depois explora empiricamente, com os dados disponíveis mais recentes, a participação efectiva dos jovens nas eleições europeias, em particular em Portugal, e já com referência para as eleições de Maio de 2014. ${ }^{1}$

Palavras-chave: Eleições; Parlamento Europeu; Portugal; voto jovem

\begin{abstract}
In the May 2014 elections to the European Parliament (EP), the issue of electoral mobilization is, again, at the center of the debate, while political parties, governments and the European Union (EU) itself try to motivate the voter to participate in the ballot and fight abstention, each poll higher. An even precise challenge is to captivate the youth vote between 18 and 24 years old. This essay thus seeks to focus specifically on the youth vote issue, which the EU itself identifies as being a concern. In this sense, the essay begins with a brief Portuguese literature review about the EP elections and especially on the youth vote, political participation of young people and citizenship; and then explores empirically, using the most recent data available, the effective participation of young people in the EP elections, particularly in Portugal and already focusing the May 2014 elections.
\end{abstract}

Keywords: Elections; European Parliament; Portugal; youth vote

\title{
Introdução
}

A participação nas eleições para o Parlamento Europeu (PE) mais do que a realização de um acto eleitoral de cariz europeu, transformou-se num desafio. Desde as eleições de 1979 que a participação nas mesmas tem diminuído, chegando mesmo a situarse abaixo dos 50\% nas eleições de 1999. Desafio ainda mais particular é cativar o voto

${ }^{1}$ O presente texto foi concluído em março de 2014. 
jovem, dos cidadãos europeus entre os 18 e os 24 anos, que, nas eleições de 2009 se cifrou pelos meros $29 \%$.

Para as eleições para o PE de 2014, a questão da mobilização eleitoral está, de novo, no cerne do debate tendo, por um lado que combater a abstenção motivada pela falta de interesse pelos assuntos europeus, uma certa hostilidade pela União Europeia (UE) e suas políticas, e o desejo de punição dos respectivos governos nacionais e da governação europeia e, por outro, que tentar passar a mensagem da natureza, objectivo e não somenos importância deste tipo de eleição.

Especificamente em relação aos jovens, embora se considerem cidadãos da UE, a sua fraca participação nestas eleições tem sido uma preocupação de políticos e de académicos. Há estudos que defendem que, em comparação com gerações passadas, os jovens de hoje passam por um prolongado período de transição para a vida adulta o que, por sua vez, tem implicações para a sua participação cívica ${ }^{2}$; outros demonstram que, embora a idade e o estatuto socio-económico seja importante na determinação da participação política, existe uma correlação evidente entre as tradições nacionais de participação cívica e política e a participação dos jovens ${ }^{3}$; mas que os jovens continuam empenhados no conceito de eleições e de participação democrática ${ }^{4}$; enquanto outros defendem que os jovens não são, de todo, politicamente apáticos, mas tanto participativos nos assuntos que lhes interessam e/ou que afectam as suas vidas, como igualmente desligados da política mainstream ${ }^{5}$.

Este ensaio pretende, assim, focar a questão do voto jovem, cuja própria UE identifica como sendo uma preocupação, tendo inclusive lançado uma campanha para

\footnotetext{
${ }^{2}$ FLANAGAN, Constance et. al. - Political Incorporation and the Protracted Transition to Adulthood: The Need for New Institutional Inventions. In Parliamentary Affairs, Volume 65, Issue 1, 2012, pp. 29-46

${ }^{3}$ SLOAM, James - "Voice and Equality': Young People's Politics in the European Union. In West European Politics, Vol. 36, Issue 4, 2013, pp. 836-858

${ }^{4}$ HENN, Matt, WEINSTEIN, Mark and WRING, Dominic - A Generation apart? Youth and political participation in Britain. In British Journal of Politics and International Relations, Vol. 4, No. 2, 2002, p. 186 ${ }^{5}$ O'TOOLE, Therese, MARSH, David and JONES, Su - Political Literacy Cuts Both Ways: The Politics of Non-participation among Young People, In Political Quarterly, Vol. 74, No.3, 2003, pp. 349-60
} 
estimular a participação dos jovens nas eleições e na vida da democracia europeia ${ }^{6}$. Nesse sentido, o ensaio começa com uma muito breve revisão da literatura em português sobre as eleições para o Parlamento Europeu e sobretudo sobre o voto jovem e a participação política dos jovens, com apontamentos para a cidadania; e depois explora empiricamente, com os dados disponíveis mais recentes, a participação efectiva dos jovens nas eleições europeias, em particular em Portugal, e já com referência para as eleições de Maio de 2014.

\section{Eleições Europeias. Cidadania, participação política dos jovens}

Durante muito tempo fui "anti-europeu” (...).

No entanto, renegando-a eu prestava inconscientemente homenagem à Europa. Adolescente, tinha adquirido, como muitos mais, sem o saber, uma educação europeia. Foi o seu rasto que me levou a preferir a humanidade às pátrias e era ele quem me convidava a apreciar o cosmopolita, era o humanismo europeu que me conduzia além da província europeia em nome do universal.

Edgar Morin

Pensar a Europa, 1988

Partimos da constatação de que em Portugal, hoje, existe um défice de envolvimento dos cidadãos na política activa. ${ }^{7} \mathrm{E}$ que os jovens, em particular, estão cada

6 Disponível em: http://pt.euronews.com/2013/05/31/ue-lanca-campanha-de-incentivo-ao-voto-dos-jovensnas-eleices-europeias/, consultada a 20/03/2014

${ }^{7}$ LOBO, Marina Costa, Portugal e a Europa: Novas Cidadanias, Lisboa, Fundação Francisco Manuel dos Santos/Comissão Europeia, 2013, pp. 81-82. 
vez mais fora da acção política, como cidadania, é um facto incontornável, susceptível de diversificadas leituras como nos demonstra um conjunto significativo de estudos sobre a cidadania política em Portugal.

$\mathrm{Na}$ verdade, muito se tem escrito sobre identidade(s), diversidade cultural, cidadania(s), temas candentes da actualidade e, muito em particular, sobre a importância da cidadania europeia no processo de integração, mas menos se tem reflectido e produzido sobre a participação portuguesa nas eleições europeias, muito concretamente sobre a jovem. A este propósito não deixa de ser oportuno referir que o interesse da academia portuguesa em relação ao exercício da cidadania política em Portugal é tardio, os estudos são muito dispersos e escasseiam as visões de conjunto bem como os estudos monográficos e comparativos sobre o empenhamento dos jovens nos actos eleitorais para o PE.

No entanto, existem excepções sobretudo a partir de 2002. Não nos vamos deter na inventariação exaustiva desses estudos, mas parece-nos importante, em termos de contextualização, referir algumas dessas obras que colocam esta temática na ordem do dia.

Em primeiro lugar, não pode esquecer-se que parte significativa dos estudos neste campo científico baseia-se, porém, num instrumento criado pela própria UE com o objectivo de monitorizar a opinião pública quer nos Estados-membros, quer nos países candidatos: o Eurobarómetro, desenvolvido pela Comissão Europeia desde 1974. Como se pode ler na primeira edição, datada de Julho desse ano. ${ }^{8}$

"A partir deste momento, a Comissão decidiu realizar inquéritos nos nove países da Comunidade, no sentido de acompanhar as tendências da opinião pública europeia no que concerne às actividades da Comunidade, em particular nas áreas com maior interesse para o público..."

Ora, o uso mais recorrente desta ferramenta tem-se registado sobretudo no quadro de artigos científicos sobre questões estreitamente ligadas à UE: atitudes face à integração,

\footnotetext{
${ }^{8}$ VALENTE, Isabel Maria Freitas; MARTINS, Ana Isabel, Vinte Anos de União Europeia. Percepções e Realidades em Portugal, col. Cadernos do CEIS20, n. ${ }^{\circ} 10$, Coimbra, CEIS20, 2009, pp. 10-11.

${ }^{9}$ CE (Comissão Europeia), Standard Eurobarometer 1 - Public Opinion in the European Union, July 1974, p. 2.
} 
identidades colectivas, alargamento, políticas comunitárias específicas e sobre a intervenção/participação dos cidadãos na vida democrática da UE.

Em segundo lugar, é importante referir que estes estudos no âmbito das Ciências Sociais ${ }^{10}$ adoptam, ainda, ferramentas de análise distintas, como inquéritos nacionais, regionais e europeus, manifestos de partidos políticos ou indicadores económicos, logrando, deste modo, explorar os processos de formação de opinião sobre a Europa, as razões que explicam os sentimentos de apoio ou cepticismo, o grau de confiança nas instituições comunitárias ou a taxa de participação nas eleições europeias.

Em terceiro lugar, deve, de igual modo, ter-se em consideração que, desde o início do século XXI, se tem assistido a um renovado interesse pelo exercício da cidadania política em Portugal em estudos, de que são exemplos, entre outros, os trabalhos de Villaverde Cabral, ${ }^{11}$ André Freire e Pedro Magalhães, ${ }^{12}$ Marina Costa Lobo, ${ }^{13}$ Carlos Jalali, ${ }^{14}$ Filipe Nunes, ${ }^{15}$ e de Boavantura Sousa Santos e João Arriscado Nunes. ${ }^{16}$

Em quarto lugar, afigura-se-nos importante sublinhar que o estudo intitulado $O s$ Jovens e a política, da autoria de Pedro Magalhães e de Jesus Sanz Moral realizado, em 2008, no âmbito do Centro de Sondagens e Estudos de Opinião da Universidade Católica

${ }^{10}$ E.G. Marks, G. and Hooghe, L., "Does identity or economic rationality drive public opinion on European integration?", PS: Political Science and Politics, vol. 37, n. ${ }^{\circ}$ 3, 2004, pp. 415-420; Sanchez-Cuenca, I., "The political bases of support for European integration", European Union Politics, vol. 1, n. ${ }^{\circ}$ 2, 2000, pp. $147-$ 171.

${ }^{11}$ CABRAL, Manuel Villaverde, “A cidadania política em Portugal”, in Análise Social, vol. XXXV (154155), Lisboa, ICS, 2000, pp. 85-113. Destaque-se, ainda, de André Freire, "O Desempenho da Democracia e Reformas", in Sociologia, problemas e práticas, n. ${ }^{\circ}$ 43, Lisboa, ISCTE, pp. 133-160 bem como a obra conjunta com Marina Lobo, Portugal a votos, Lisboa, ICS, 2002.

${ }^{12}$ FREIRE, André; MAGALHÂES, Pedro, A Abstenção Eleitoral em Portugal, Lisboa, ICS, 2002.

${ }^{13}$ LOBO, Marina Costa, "As Eleições ao Parlamento Europeu em Portugal", in Portugal Contemporâneo, (coord.) António Costa Pinto, Lisboa, Dom Quixote, 2005, pp. 193-196. Leia-se, também, FREIRE, André, LOBO, M. C., MAGAlHÃES, P. C. (cood.), Comportamentos Eleitorais e Atitudes Políticas, 1973-2002, Lisboa, ICS, 2005.

${ }^{14}$ JALALI, Carlos, "A investigação do comportamento eleitoral em Portugal: história e perspectivas futuras", in Análise Social, vol. XXXVIII (167), Lisboa, ICS, 2003, pp. 545-572; "Nova governação, nova cidadania? Os cidadãos e a política em Portugal”, in Tekhné - Revista de Estudos Politécnicos, vol. 2, nº 4, 2005, pp. 2938.

15 NUNES, Filipe, "Eleições de segunda ordem em Portugal: O caso das europeias de 2004", in Análise Social, vol. XL (177), Lisboa, ICS, 2000, pp. 795-813.

${ }^{16}$ SANTOS, Boaventura de Sousa; NUNES, João Arriscado, "Introduction: Democracy, Participation and Grassroots Movements in Contemporary", South European Society \& Politics, Volume 9, Issue 2, 2004. Texto disponível on-line em: http://dx.doi.org/10.1080/1360874042000253465 [Acesso em 24 de Março de 2013]. 
Portuguesa para a Presidência da República demonstra de forma inequívoca "uma cidadania consciente dos défices de participação e envolvimento político na sociedade portuguesa e das suas consequências potencialmente nefastas para a qualidade da nossa democracia." $" 17$

É oportuno ainda, referir que no âmbito das celebrações do Ano Europeu da Cidadania (2013), o Eurobarómetro n. ${ }^{\text {}} 78$ foi dedicado às questões da cidadania e as conclusões relativas ao exercício dos direitos políticos, à participação eleitoral nas eleições para o PE colocam o nosso país entre os que menos eleitores votam.

Finalmente, como forma de combate ao progressivo desinteresse e envolvimento dos cidadãos portugueses no projecto europeu e, muito particularmente, dos jovens uma série de iniciativas têm vindo a ser promovidas por várias instituições nacionais e europeias. De entre elas, permitir-nos-íamos destacar as que nos parecem mais pertinentes.

Assim, o Centro de Informação Europeia Jacques Delors, desde 1995, e baseado na convicção de que uma União Europeia mais forte e solidária não dispensa uma cidadania mais participativa, bem como cidadãos mais informados e conscientes do seu contributo para o futuro do projecto europeu, tem estimulado, organizado e promovido uma série de cursos, ciclos de estudos, seminários, encontros e estágios sobre temas relacionados com a União Europeia. De entre eles, as acções de formação sobre Cidadania nas escolas, as formações para Professores sobre "Cidadania e a dimensão europeia na educação" e as sessões de informação e debate sobre as "Eleições Europeias de 2009" foram e são marcos fundamentais na promoção de uma cidadania jovem consciente e activa.

É ainda de sublinhar o projecto "Tu na Europa"18 - uma iniciativa dirigida a jovens que visa promover a Cidadania Europeia, especificamente a participação nas eleições Europeias de Maio de 2014, capacitando os jovens para fazer uma escolha informada promovida pelo Conselho Nacional de Juventude (enquanto ramo nacional da League of Young Voters) em parceria com: Instituto Português do Desporto e Juventude, I.P, entre outros.

\footnotetext{
${ }^{17}$ Cf. http://presidencia.pt/archive/doc/Os_jovens_e_a_politica.pdf. [Acesso em 24 de Março de 2013].

${ }^{18}$ Cf. http://www.portalocplp.org/media/company/1/Apresentao_Projeto.pdf [Acesso em 24 de Março de 2013].
} 
Nesta mesma linha, O Team Europe da Comissão Europeia ${ }^{19}$ tem ministrado junto das escolas (ensino secundário e superior) um conjunto de acções de informação sobre as eleições europeias de 2014 à semelhança do que aconteceu em outros actos legislativos europeus.

À luz deste panorama, em que se tecem estratégias diferentes e uma panóplia de visões diferenciadas, muitas questões se levantam: Como tornar o projecto europeu novamente atraente para os seus cidadãos? Como dar uma resposta às preocupações diárias das pessoas? De que forma os jovens podem $(\mathrm{Re})$ apaixonarem-se pela Europa?

Estas interrogações pretendem constituir pistas de reflexão tão ao gosto de um dos nossos maiores legados ontológicos enquanto europeus - o do questionamento, como insistiu Heidegger.

\section{A participação dos jovens nas eleições de 2009 e perspectivas para as de 2014}

Os jovens dispersam os seus interesses por uma panóplia de áreas (protecção do ambiente e dos animais, educação, emprego, discriminação, direitos humanos, por exemplo), sendo rara a referência à política e pouco efectiva a sua participação política, nomeamente no contexto de eleições.

Uma caracterizaçao socio-demográfica demonstra que o perfil do abstencionista nas eleições para o PE está relacionado com a idade e com a situação socio-económica, ou seja, são os jovens e os economicamente mais desfavorecidos quem mais se abstém nestas eleições. Os dados relativos à eleição de 2009 demonstram claramente este facto, sendo que que o abstencionismo jovem nas eleições para o PE está relacionado com duas alterações políticas significativas: a controvérsia em torno da legitimidade do processo de integração europeia e o decréscimo da participação nestas eleições em geral $^{20}$.

\footnotetext{
${ }^{19}$ Rede de conferencistas independentes da Comissão Europeia, especialista em temas específicos da União Europeia e que estão disponíveis para participar em colóquios, seminários, acções de formação, etc.

${ }^{20}$ BOUZA, Luis - Addressing youth absenteeism in European elections. Brussels: League of Young Voters in Europe Aisbl, 2014, p. 7
} 


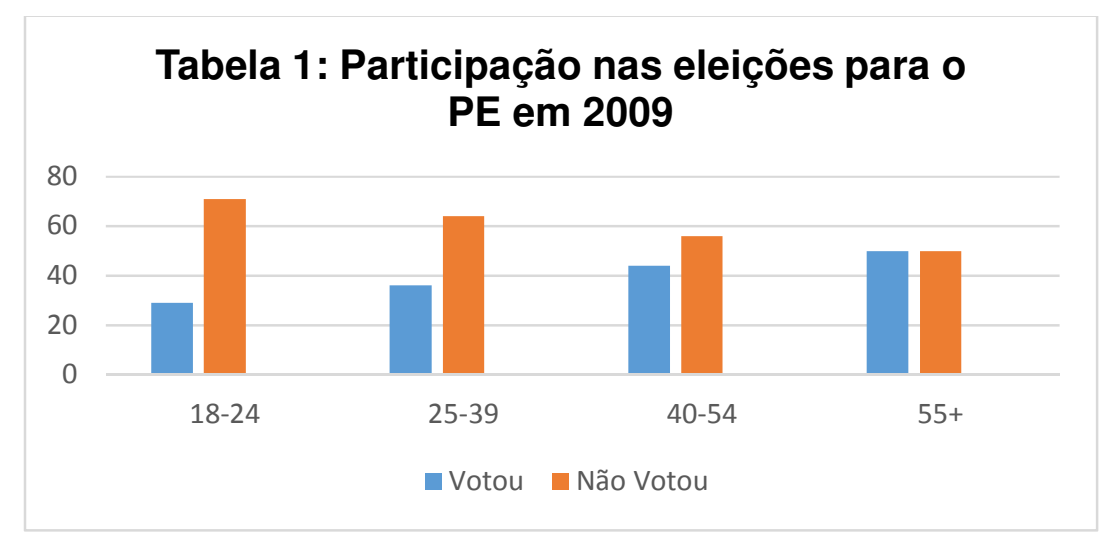

Fonte: Special Eurobarometer 320: Post-election survey report, 2009, p. 14

Enquanto que a percentagem de adultos vai diminuindo a sua abstenção, a percentagem dos jovens é assustadoramente grande. $71 \%$ dos jovens europeus não votaram em 2009 (contra 50\% dos mais idosos), na linha aliás do que acontecera nas eleições anteriores em 2004. E, embora, a abstenção tenha crescido praticamente em todas as categorias (género, profissão, habilitações literárias), entre uma e outra eleição, o aumento da abstenção é particularmente evidente entre a categoria dos jovens, com uma subida percentual de quatro pontos.

Uma análise mais detalhada verifica que, primeiro, praticamente um terço dos jovens entre os 18 e os 24 anos não vota nunca nas eleições europeias, enquanto os restantes $38 \%$, decidem não votar em diferentes alturas: $11 \%$ fazem-nos meses antes das mesmas, o que sugere que a sua decisão foi ponderada; $8 \%$ umas semanas antes; $17 \%$ apenas uns dias antes; e 14\% tomam essa decisão no próprio dia das eleições, podendo ser considerada como uma decisão de "último minuto". Comparativamente, o grupo dos jovens é, de facto, o mais propício a decidir na véspera, tanto por a sua experiência eleitoral ser mais limitada como por serem mais hesitantes antes de fazerem a sua escolha. 


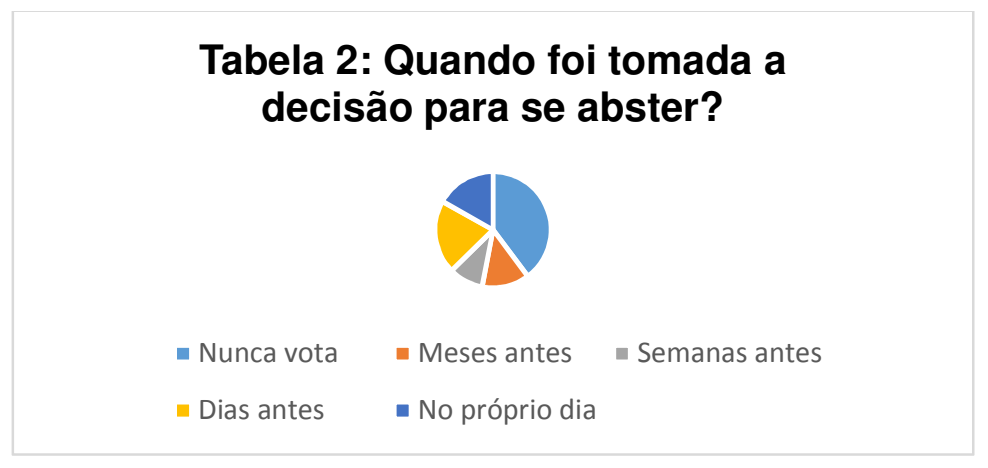

Fonte: Special Eurobarometer 320: Post-election survey report, 2009, p. 24

Por outro lado, o facto de $68 \%$ dos jovens não se sentir próximo de nenhum partido político $^{21}$, também prejudica a participação eleitoral deste grupo, sendo que no que diz respeito à participação eleitoral existe uma correlação entre idade mais avançada, com maiores habilitações académicas e maior sentimento de pertença à UE, e maior taxa de participação nas eleições europeias.

Igualmente importante é a questão da informação: um cidadão informado pode tomar as suas decisão com uma base mais sólida. Nas últimas eleições, 44\% dos jovens europeus entenderam que tiveram a informação necessária para fazer a sua escolha eleitoral, enquanto $50 \%$ afirmam precisamente o contrário ${ }^{22}$. Mais uma vez se confirma que as categorias mais bem informadas (maiores de 40 anos ou mais, com maiores habilitações académicas e mais expostos às campanhas eleitorais) são aquelas que efectivamente mais participam no acto eleitoral.

Em relação à amostra dos que votaram, que no caso do grupo dos jovens dos 18 aos 24 anos, foi de $29 \%$, os assuntos que os motivaram a votar estão relacionados com o crescimento económico (46\%), o desemprego (41\%), o futuro das pensões (11\%) e, finalmente, o papel da UE na política internacional (23\%).

\footnotetext{
${ }^{21}$ Special Eurobarometer 320: Post-election survey report, 2009, p. 36

${ }^{22}$ Idem, p. 40
} 


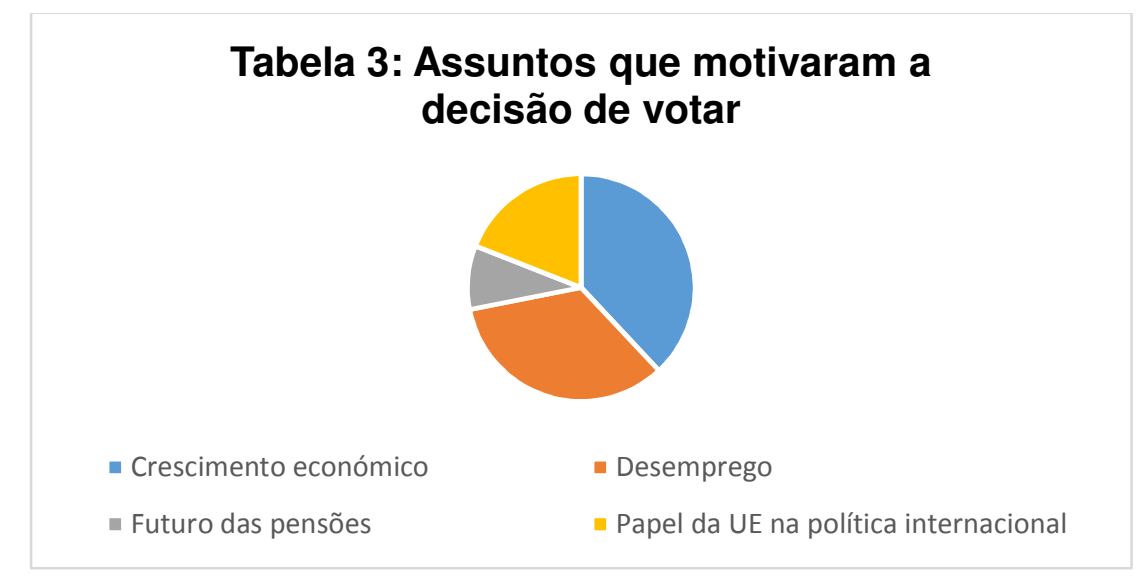

Fonte: Special Eurobarometer 320: Post-election survey report, 2009, p. 63

Num estudo recente, precisamente dedicado às atitudes dos jovens europeus (dos 15 aos 30 anos) perante a participação política em diferentes eleições, o seu conhecimento e intenção de participar nas próximas eleições para o PE e a probabilidade de votarem nas mesmas, surgiu a constação chocante de que $43 \%$ dos jovens ${ }^{23}$ não sabem sequer que os membros do PE são eleitos directamente pelos cidadãos dos Estados-membros.

Neste aspecto, os jovens portugueses, com o país prestes a celebrar os 30 anos da adesão à UE em 2016, já adquiriram uma certa noção cívica deste tipo de eleições, pelo que $61 \%$ (um número bem acima da média comunitária) sabem que esta eleição é directa, contra $29 \%$ que não o sabem ${ }^{24}$.

Contrariamente a esta "semi-falta" (uma vez que os números entre os que conhecem e os que desconhecem são próximos) de conhecimento, e também em contradição com os números de participação nas eleições anteriores, para este ano, 64\% dos jovens europeus diz que é provável que vão votar, contra $35 \%$ que diz o oposto. De entre estes, contudo,

\footnotetext{
${ }^{23}$ Flash Eurobarometer 375: European youth: participation in democratic life report, 2013, p. 18

${ }^{24}$ Idem, p. 19
} 
apenas $28 \%$ afirma que irá concerteza votar, enquanto $11 \%$ diz que está absolutamente seguro de que não o fará ${ }^{25}$.

De novo, especificamente em relação aos jovens portugueses, os resultados indicam que $56 \%$ deles irá votar, contra $42 \%$ que não irá. A intenção de ir votar é satisfatória, mas aquém de números mais encorajadores da Bélgica, onde o voto é normalmente obrigatório (80\%), dos Países Baixos (76\%), da Suécia, Itália e Irlanda, e do Luxemburgo e Malta $(75 \%)^{26}$.

Das razões apontadas para votar a importância da democracia foi apontada como o maior incentivo para votar (94\%), enquanto 90\% indicam a importância da Europa e das eleições europeias, e $83 \%$ acreditam que votar é o modo indicado para influenciar as decisões políticas. Números igualmente significativos indicam que votar é uma obrigação moral $(72 \%)$, ou que votar tem um impacto significativo nos assuntos que os afectam directamente (68\%). Já $70 \%$ simplesmente votam sempre ou são interessados genericamente em política e eleições $(65 \%)$.

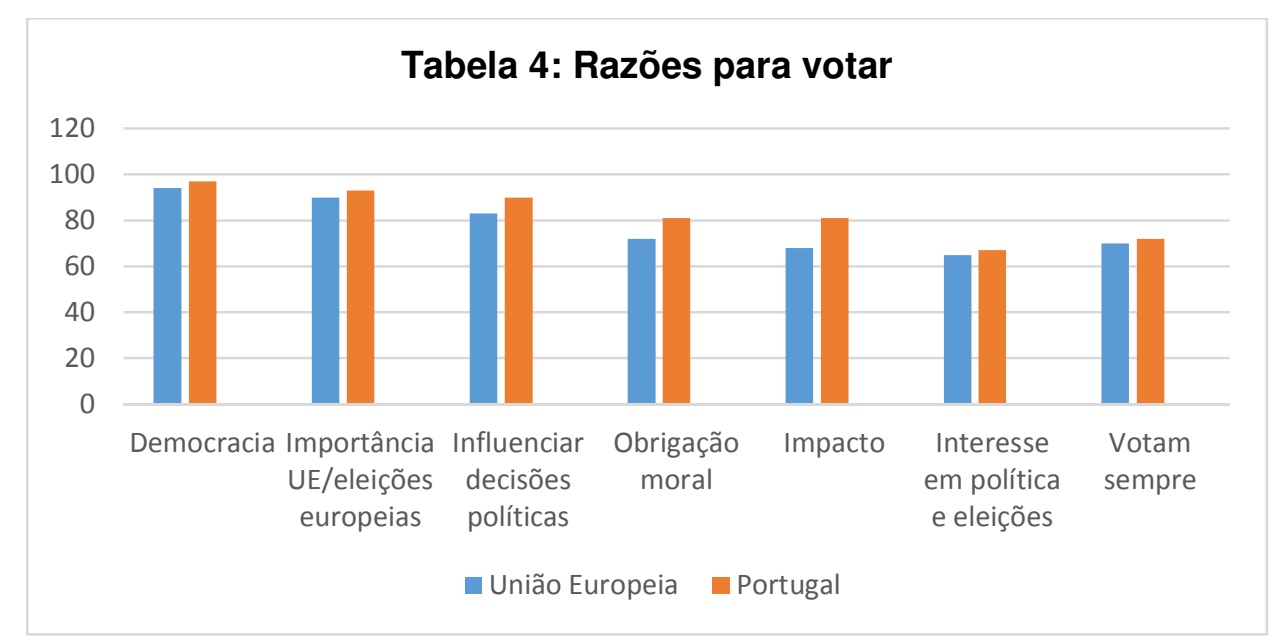

Fonte: Flash Eurobarometer 375: European youth: participation in democratic life report, 2013, pp. 25-32

\footnotetext{
${ }^{25}$ Idem, p. 21

${ }^{26}$ Idem, p. 22
} 
Os jovens portugueses estão em sintonia com estes números, sendo que 97\% deles apontou a democracia como o maior incentivo para votar, $90 \%$ que tal influencia as decisões políticas, $81 \%$ que votar é tanto uma obrigação moral, como tem um real impacto nos assuntos que lhes interessam; enquanto $72 \%$ dizer votar sempre e $5 \%$ menos refere demonstrar interesse pela política em geral e pelas eleições em particular. De salientar, que em todos os itens, Portugal figura sempre acima da média comunitária, figurando em todos eles nos primeiros dez, e num deles (votar tem um impacto em assuntos que me afectam) é mesmo o segundo, apenas atrás da Bulgária e apenas por $1 \%$.

No lado oposto, dos que respondem que não tencionam votar, $64 \%$ justifica que o seu voto não mudará nada, não terá importância; $61 \%$ que não estão suficientemente informados para votar; uma percentagem menor (56\%), por sua vez, não votará pois entende que o PE não lida suficientemente com os problemas que os preocupam; outra ligeiramente menor diz-se não interessada na política e nas eleições europeias (54\%) ou na política e eleições em geral (47\%); outros nunca votam (37\%) e 18\% são contra a Europa/União Europeia.

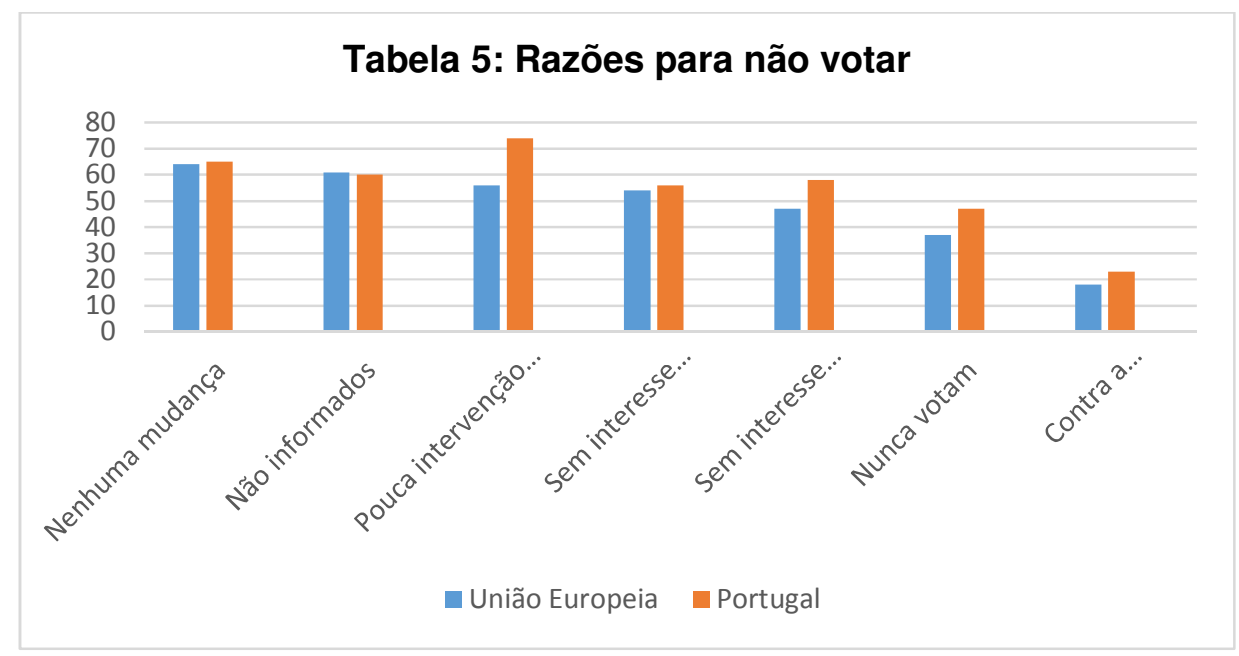

Fonte: Flash Eurobarometer 375: European youth: participation in democratic life report, 2013, pp. 35-42 
De salientar a este respeito, os valores bastante díspares em relação à média europeia no que diz respeito à percepção que os jovens portugueses têm em relação à pouca intervenção do PE no assuntos que os interessam, ao desinteresse pela política e eleições em geral, e ao facto de nunca votarem, tudo percentagens com uma diferença dos $10 \%$ ou acima.

Àparte o factor idade, e como seria de esperar, neste grupo há factores sociodemográficos que influenciam a decisão de votar ou não: uma percentagem maior de mulheres afirma que vai votar em comparação com os homens; quem concluiu os seus estudos numa idade mais nova tem maior tendência a não votar; assim como os que são trabalhadores manuais ou empregados por conta-própria, ao contrário dos que trabalham por conta de outrém; e, por fim, aqueles que fizeram parte de alguma associação (de jovens, não-governamental) têm mais propensão para votar ${ }^{27}$.

\section{Notas finais}

Na linha de numerosos estudos, que têm concluído que, em termos de atitude e de comportamento, os jovens estão menos predispostos para participar no processo político, e especiamente, em votar do que cidadãos mais velhos, este ensaio reforça essa assumpção, especificamente no que diz respeito à participação nas eleições para o PE.

Uma baixa taxa de participação enfraquece a legitimidade democrática da União Europeia (UE) e, em última análise, é um indicador da "saúde da democracia" na mesma. E, apesar das previsões optimistas em relação à participação dos jovens nas próximas eleições, os dados acima devem, todavia, ser lidos com precaução, na medida em que, primeiro é difícil prever com tanta antecedência a tendência da participação; segundo devido à grande disparidade com os resultados das eleições de 2009.

\footnotetext{
${ }^{27}$ Idem, p. 23
} 
Assim, embora animadoras, estas perspectivas não devem toldar os candidatos nacionais e respectivos partidos, assim como o PE e a UE como um todo, de utilizar os instrumentos disponíveis para chegar aos jovens e lidar com os problemas que os interessam. Como a taxa de participação dos jovens é baixa, os partidos também nomeiam poucos candidatos jovens, o que por sua vez determina que são poucos os eurodeputados jovens eleitos, logo menos representativos dos seus interesses o que, tudo conjugado, se transforma num ciclo vicioso, não vencedor e lesivo dos interesses de união dos povos da Europa.

Mas a razão deste afastamento não estará, também ela, na questão formulada por Lucien Daloz, em 1999: "L'Europe peut-elle se faire sans dimension spirituelle?"28 ou como muito bem questiona Jacques Delors num prefácio à obra Europe. Utopie et Réalisme: "L'Europe a-t-elle une âme?"29

\section{Algumas referências}

BOUZA, Luis - Addressing youth absenteeism in European elections. Brussels: League of Young Voters in Europe Aisbl, 2014, ISSN 2032 - 9938

CABRAL, Manuel Villaverde, "A cidadania política em Portugal”, in Análise Social, vol. XXXV (154-155), Lisboa, ICS, 2000, pp. 85-113

CE (Comissão Europeia), Standard Eurobarometer 1 - Public Opinion in the European Union, July 1974, p. 2

DALOZ, Lucien, “L'Europe peut-elle se faire sans dimension spirituelle?", in Revue Études, tome 391, n. 3 (3.913), septembre, 199, pp. 215-228

DELORS, Jacques, "Préface", in Europe. Utopie et Réalisme, Paris, Études Hors-Série, 2011, p. 5

${ }^{28}$ DALOZ, Lucien, "L'Europe peut-elle se faire sans dimension spirituelle?", in Revue Études, tome 391, n. 3 (3.913), septembre, 199, pp. 215-228.

${ }^{29}$ DELORS, Jacques, "Préface", in Europe. Utopie et Réalisme, Paris, Études Hors-Série, 2011, p. 5. 
E.G. Marks, G. and Hooghe, L., "Does identity or economic rationality drive public opinion on European integration?", PS: Political Science and Politics, vol. 37, n. 3, 2004, pp. $415-420$

FLANAGAN, Constance et. al. - Political Incorporation and the Protracted Transition to Adulthood: The Need for New Institutional Inventions. In Parliamentary Affairs, Volume 65, Issue 1, 2012, pp. 29-46

Flash Eurobarometer 375: European youth: participation in democratic life report, 2013

FREIRE, André, "O Desempenho da Democracia e Reformas", in Sociologia, problemas e práticas, n. ${ }^{\circ}$ 43, Lisboa, ISCTE, pp. 133-160

FREIRE, André, LOBO, M. C., MAGAlHÃES, P. C. (cood.), Comportamentos Eleitorais e Atitudes Políticas, 1973-2002, Lisboa, ICS, 2005

FREIRE, André; MAGALHÂES, Pedro, A Abstenção Eleitoral em Portugal, Lisboa, ICS, 2002

HENN, Matt, WEINSTEIN, Mark and WRING, Dominic - A Generation apart? Youth and political participation in Britain. In British Journal of Politics and International Relations, Vol. 4, No. 2, 2002, pp. 167-192

http://presidencia.pt/archive/doc/Os_jovens_e_a_politica.pdf. [Acesso em 24 de Março de 2013].

http://pt.euronews.com/2013/05/31/ue-lanca-campanha-de-incentivo-ao-voto-dosjovens-nas-eleices-europeias/ [Acesso em 24 de Março de 2013]

http://www.portalocplp.org/media/company/1/Apresentao_Projeto.pdf [Acesso em 24 de Março de 2013]

JALALI, Carlos, "A investigação do comportamento eleitoral em Portugal: história e perspectivas futuras", in Análise Social, vol. XXXVIII (167), Lisboa, ICS, 2003, pp. 545572

JALALI, Carlos, "Nova governação, nova cidadania? Os cidadãos e a política em Portugal”, in Tekhné - Revista de Estudos Politécnicos, vol. 2, n 4, 2005, pp. 29-38

LOBO, Marina Costa, “As Eleições ao Parlamento Europeu em Portugal”, in Portugal Contemporâneo, (coord.) António Costa Pinto, Lisboa, Dom Quixote, 2005, pp. 193-196 
LOBO, Marina Costa, Portugal e a Europa: Novas Cidadanias, Lisboa, Fundação Francisco Manuel dos Santos/Comissão Europeia, 2013, pp. 81-82

LOBO, Marina, Portugal a votos, Lisboa, ICS, 2002

NUNES, Filipe, "Eleições de segunda ordem em Portugal: O caso das europeias de 2004”, in Análise Social, vol. XL (177), Lisboa, ICS, 2000, pp. 795-813

O'TOOLE, Therese, MARSH, David and JONES, Su - Political Literacy Cuts Both Ways: The Politics of Non-participation among Young People, In Political Quarterly, Vol. 74, No.3, 2003, pp. 349-60

PÍNDARO, Nemeica.7.12-13

SANCHEZ-CUENCA, I., "The political bases of support for European integration", European Union Politics, vol. 1, n. ${ }^{\circ}$ 2, 2000, pp. 147-171

SANTOS, Boaventura de Sousa; NUNES, João Arriscado, "Introduction: Democracy, Participation and Grassroots Movements in Contemporary", South European Society \& Politics, Volume 9, Issue 2, 2004. Texto disponível on-line em: http://dx.doi.org/10.1080/1360874042000253465 [Acesso em 24 de Março de 2013].

SLOAM, James - "Voice and Equality': Young People's Politics in the European Union. In West European Politics, Vol. 36, Issue 4, 2013, pp. 836-858

Special Eurobarometer 320: Post-election survey report, 2009

TEPEROGLOU, Eftichia - A Chance to Blame the Government? The 2009 European Election in Southern Europe. In South European Society and Politics, Vol. 15, No. 2, 2010, pp. $247-272$

VALENTE, Isabel Maria Freitas; MARTINS, Ana Isabel, Vinte Anos de União Europeia. Percepções e Realidades em Portugal, col. Cadernos do CEIS20, n. ${ }^{\circ} 10$, Coimbra, CEIS20, 2009, pp. 10-11. 